\title{
Determining Malaria Hotspot Using Climatic Variables and Geospatial Technique in Central Urban Area of Ibadan, Southwest, Nigeria
}

\section{Ademola Akinbobola ${ }^{1^{*}}$ and Isotein A lkiroma $^{2}$}

${ }^{1}$ Department of Meteorology and Climate Science, Federal University of Technology, Akure, Nigeria

${ }^{2}$ Centre for Environmental Research, Institute of Biomedical and Environmental Health Research, School of Science and Sport University of the West of Scotland, Nigeria

"Corresponding author: Ademola Akinbobola, Department of Meteorology and Climate Science, Federal University of Technology, Akure, Nigeria, Tel: +234-8034619238; E-mail:

aakinbobola@futa.edu.ng

Received date: February 21, 2018; Accepted date: March 27, 2018; Published date: March 31, 2018

Copyright: (c) 2018 Akinbobola A, et al. This is an open-access article distributed under the terms of the Creative Commons Attribution License, which permits unrestricted use, distribution, and reproduction in any medium, provided the original author and source are credited.

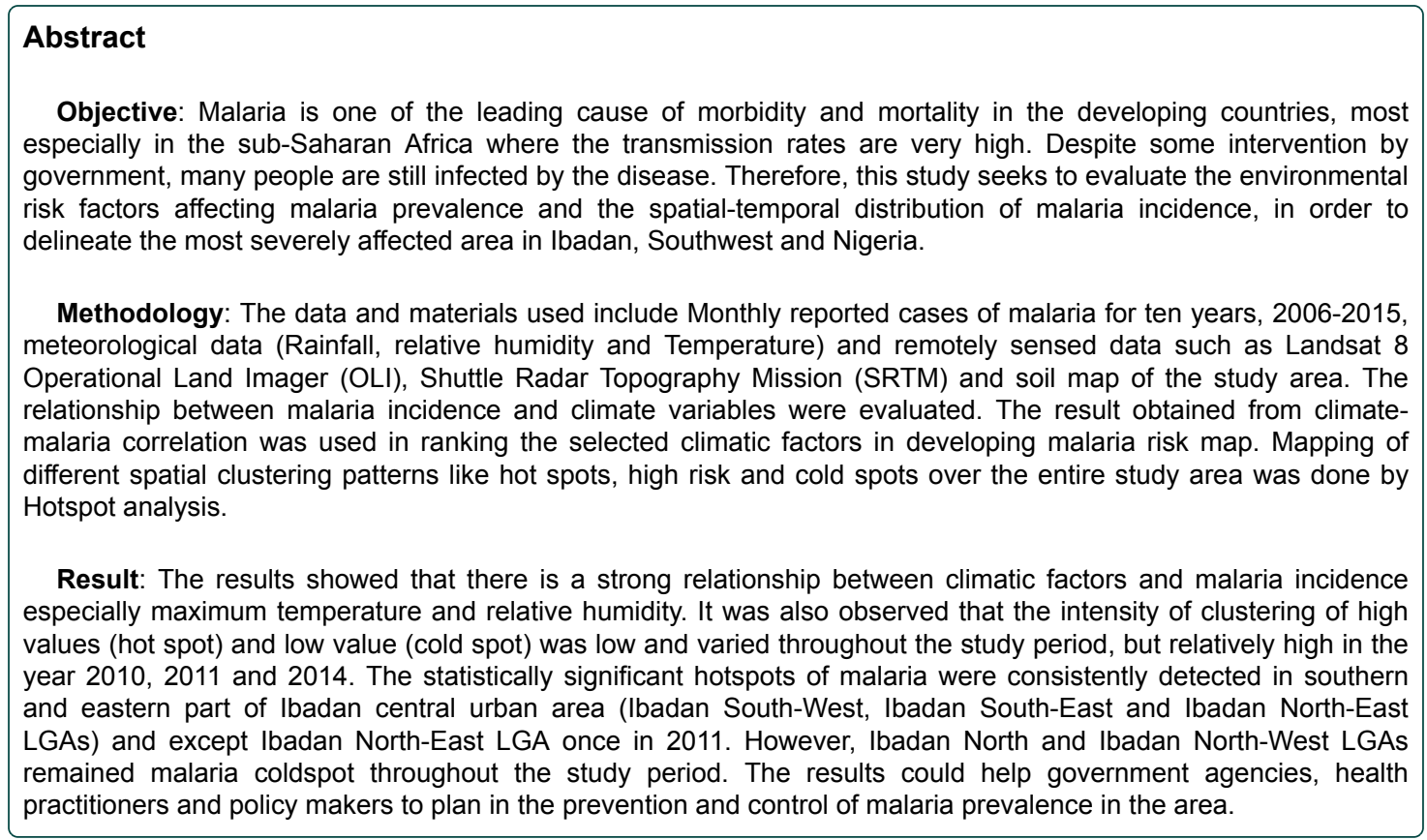

Keywords: Climatic variables; Malaria; Hotspot; Temperature; Rainfall

\section{Introduction}

Malaria is one of the leading causes of morbidity and mortality in the developing world, especially sub-Saharan Africa where the transmission rates are highest and where it is considered to be a major impediment to economic development [1]. The vast majority of cases (85\%) were reported in the African Region, followed by the South-East Asia (10\%) and Eastern Mediterranean Regions (4\%). In the same year, it accounted for an estimated 863,000 deaths, of which (89\%) were in the African Region, followed by the Eastern Mediterranean (6\%) and the South-East Asia Regions (5\%) [2]. Malaria is a vector borne disease. The vector Anopheles mosquitoes are particularly influenced by environmental conditions. Indeed, arthropod vectors in general, and insect vectors in particular are very sensitive to their environments, which in turn determines their presence, and development. As a consequence, climatic as well as landscape and land cover factors greatly influence the spatial distribution of vectors and the diseases they transmit [3]. Nowadays Remote Sensing techniques provide valuable information on such environmental conditions. Several studies have used Remote Sensing imagery and Geographical Information System (GIS) techniques to map the distribution of vector species at different spatial scales such as the entire world, continent, national, regional, even at small village level. According to [4], in endemic areas, mainly in tropical and subtropical regions, these vector maps are designed to improve vector control, which is currently one of the essential methods in limiting the burden of important vector-borne diseases such as malaria or dengue fever. In disease free areas, analyzing the link between the environment and potential vector distribution may help evaluate the risk of emergence of the disease, and lead to better mitigation and control measure of the invasive vector species. The non-availability of GIS-based malaria risk maps in Ibadan central urban area, has led to a decline in studies showing malaria distribution in relation to environmental risk factors through the application of geo-spatial techniques. As we observed in the previous studies of Remote Sensing and GIS use in combination as a tool to map the distribution of vectors at different spatial scale. The Nigeria government policy towards malaria control and eradication 
has given due consideration to communicable diseases like malaria free diagnosis especially at lower health facilities level free antimalarial drugs, free distribution of ITNs to all and free indoor residual spraying of houses. Despite the government intervention, many people are still suffering from malaria. If all the above efforts could be supported by developing the malaria risk and hotspot map, the result of prevention and control of malaria would be better than today's situation.

Therefore, this study will identify and map the malaria risk and hotspot areas by considering many geographical and environmental factors that make condition suitable for breeding site of mosquito in the study areas. The final output makes it possible to plan the control measures to be implemented by giving priority to high risk areas. This situation greatly increases the cost, time and energy efficiency of the malaria control and prevention program.

\section{Methodology}

\section{The study area}

The study area, Ibadan central urban area, consists of five local government areas (LGAs), which is about $15 \%$ of Ibadan's total land area. The five LGAs in the study area are Ibadan North, Ibadan NorthEast, Ibadan North-West, Ibadan South-East and Ibadan South-West local government areas. its geographical location extends approximately from longitude $3^{\circ} 48^{\prime}$ to $3^{\circ} 58^{\prime}$ East of the Greenwich Meridian, and latitude $7^{\circ} 18^{\prime}$ to $7^{\circ} 28^{\prime}$ north of the Equator. The remaining $85 \%$ of Ibadan's total land area consists of six LGAs and classified as either predominantly peri-urban or rural settlements Figure 1.

Ibadan is located in south-western Nigeria, the capital of Oyo State. It exhibits the typical West African Monsoon climate marked by distinct seasonal shifts in wind patterns. Between March and October, the city is under the influence of moist maritime south-west monsoon winds which blow inland from the Atlantic Ocean, marking the rainy season. The dry season occurs from November to February when the dry dust laden winds blow from the Sahara desert. The area experiences high relative humidity and generally two rainfall maxima regimes during the rainfall period of March to October. The mean annual rainfall of about $1,205 \mathrm{~mm}$, falling in approximately 109 days with two rainfall peaks in June and September. The mean temperatures are highest at the end of the harmattan (averaging $28^{\circ} \mathrm{C}$ ), that is from the middle of January to the onset of the rains in the middle of March. During the rainfall months, average temperatures are relatively high, between $24^{\circ} \mathrm{C}$ and $25^{\circ} \mathrm{C}$, while annual fluctuation of temperature is about $6^{\circ} \mathrm{C}$

The main land use of the study area is dominated by built up land (all residential, commercial and industrial areas, settlement and infrastructures) and less vegetation cover (trees, shrub land, natural and semi-natural vegetation). The vegetation and wetlands are threatened by urban expansion. Three major landforms of hills, plains and river valleys dominate the whole landscape of Ibadan. The average elevation is $230 \mathrm{~m}$ above mean sea level. Ibadan city is also characterized by poor housing environmental sanitation especially in area with high density of low income populations [5].

\section{Types of data}

The data and materials used include monthly clinical data (malaria cases), climatic data (rainfall and temperature) and remotely sensed data such as Landsat 8 Operational Land Imager (OLI). Shuttle Radar Topography Mission (SRTM) and soil map of the study area. Types of data used and their sources are described in Table 1.

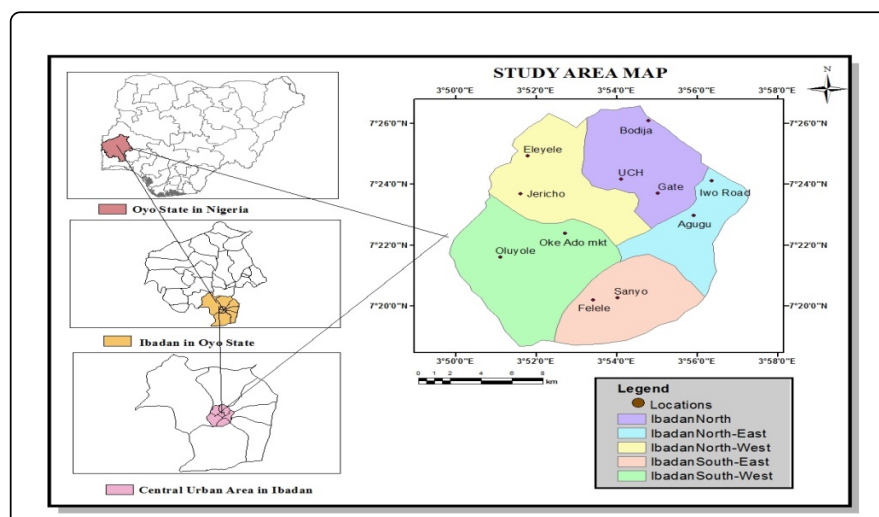

Figure 1: Location map of the Study Area.

\section{Method of analysis}

Software and material utility: The software types used for different types of activities in the process of determining malaria hotspot areas in this study include: Arc GIS 10.2, AHP priority calculator and Google earth. Types of software and material used and their applications are described in Table 2.

Climate-Malaria correlation analysis: A retrospective survey design that involved the use of historical data of climate variables and medical case reports from Ibadan urban area was adopted. The data includes weather data on temperature, rainfall and relative humidity from the Nigeria Meteorological Agency and medical records of malaria cases from the Oyo State Ministry of Health for a period of eight years (2008-2015).

\begin{tabular}{|c|c|c|c|c|}
\hline No. & Data & Type & Sources & Remarks \\
\hline 1 & $\begin{array}{l}\text { Map of the study } \\
\text { area (derived) }\end{array}$ & Spatial & $\begin{array}{ll}\text { ESRI } & \text { Geo- } \\
\text { database } & \end{array}$ & Shape file \\
\hline 2 & $\begin{array}{l}\text { Malaria cases } \\
\text { (Clinical data) }\end{array}$ & Attribute & Oyo State $\mathrm{MoH}$ & 8 years \\
\hline 3 & $\begin{array}{l}\text { Meteorological } \\
\text { data (Ground) }\end{array}$ & Attribute & NIMET & 8 years \\
\hline 4 & $\begin{array}{l}\text { Meteorological } \\
\text { data (Remotely } \\
\text { sensed) }\end{array}$ & Spatial & ERA Interim & 15 years \\
\hline 5 & $\begin{array}{l}\text { Shuttle Radar } \\
\text { Topographic } \\
\text { Mission (SRTM) }\end{array}$ & Spatial & $\begin{array}{lr}\text { United } & \text { State } \\
\text { Geological } & \text { Survey } \\
\text { (USGS) }\end{array}$ & Scale $1: 100,000$ \\
\hline 6 & Landsat8 (OLI) & Spatial & USGS & p191r055,2015 \\
\hline 7 & Soil map & Spatial & $\begin{array}{l}\text { Food } \\
\text { Agriculture } \\
\text { Organization } \\
\text { United } \\
\text { (FAO) }\end{array}$ & Shape file \\
\hline
\end{tabular}

Table 1: Type of data used and their sources. 


\begin{tabular}{|c|c|c|}
\hline No. & $\begin{array}{l}\text { Software and } \\
\text { material Used }\end{array}$ & Utility \\
\hline 1 & Arc GIS 10.2 & $\begin{array}{l}\text { Generation of maps, Land use/land cover image } \\
\text { classification, Image processing, Reclassification } \\
\text { of factors, for weighted overlay analysis, Spatial } \\
\text { statistical analysis. }\end{array}$ \\
\hline 2 & Minitab & $\begin{array}{l}\text { Documentation, statistical analysis and } \\
\text { presentation. }\end{array}$ \\
\hline 3 & $\begin{array}{l}\text { AHP priority } \\
\text { calculator }\end{array}$ & $\begin{array}{l}\text { Multi Criteria Evaluation (MCE) and Giving } \\
\text { weight. }\end{array}$ \\
\hline 4 & $\begin{array}{l}\text { Google } \\
\text { (web) }\end{array}$ & $\begin{array}{l}\text { Taking coordinates and assessment of } \\
\text { geographical locations. }\end{array}$ \\
\hline
\end{tabular}

Table 2: Software types and their application areas.

The historical daily weather data were obtained from surface synoptic weather station for a period of (2008-2015). Data on malaria cases reported on monthly basis by place of diagnoses were obtained from government hospitals and clinics in each of the five (5) LGAs. The medical record contains only the aggregate number of malaria cases per LGA but the number of malaria cases from each of the health center was not known. Since malaria data was given on monthly basis, all climatic variables were analyzed monthly in order to match with malaria data. Monthly mean temperature was calculated from the daily minimum and maximum temperature and so also other daily climatic data were calculated on monthly basis. Pearson correlation analysis was used to ascertain the relationship between malaria and rainfall, malaria and relative humidity, and malaria and temperature. The correlation analysis was then carried out using data for each month of the year but taking the total number of year of study altogether. In this way, all January rainfall data between 2008 and 2015 were combined to form a series; the same was done for February and so on to December. Further, other climatic variables and malaria data were treated in the same manner. The correlation coefficients were plotted against months. Hence, correlation coefficients of time series of monthly climatic variables and monthly malaria incidence were analyzed. The result obtained from climate-malaria correlation was used in ranking the selected climatic factors in developing malaria risk map.

Malaria hotspot analysis: Mapping or identification of different spatial clustering patterns like hot spots, high risk and cold spots over the entire study area was done by Hotspot analysis [6-8] in Arc GIS 10.2 environment. The malaria data were pooled as per GIS data format and records were attached to the polygons of prepared LGA(s) in GIS environment. The hotspot analysis was performed to identify the LGA(s) with higher or lower malaria cases than expected under the null hypothesis of spatial randomness or a concentration of malaria that cannot be explained by chance.

Environmental factors for malaria incidence were selected and used to generate malaria risk map for the study area. These environmental factors were selected based on previous research works. According to this elevation, temperature, slope, soil, rainfall, land use land cover type and proximity to water bodies and swamps are selected as major environmental factors for malaria incidence. For each environmental factors mentioned above maps were generated and then reclassified depending on their suitability for mosquito breeding. In the process of reclassification, new values [1-5] were assigned and they represent very low, low, moderate, high and very high malaria risk level, respectively. To see the influence of each factor, weight computation was done by pair wise comparison matrix. And finally weighted overlay was carried out using Arc Map 10.2 to generate the final malaria risk map of the study area. To determine most severely affected LGA(s) malaria hotspot and risk maps were compared.

\section{Results}

\section{Correlation between climatic variables and malaria incidence}

Correlation coefficients between the climatic variables and malaria prevalence is presented in Table 3.

\begin{tabular}{|l|l|l|l|l|l|l|l|l|l|l|l|l|}
\hline Variable & Jan & Feb & Mar & April & May & Jun & Jul & Aug & Sep & Oct & Nov & Dec \\
\hline RF & -0.223 & 0.089 & 0.473 & -0.166 & 0.002 & -0.017 & -0.510 & 0.451 & -0.070 & 0.488 & 0.424 & -0.044 \\
\hline RH & 0.580 & 0.456 & -0.111 & 0.732 & 0.814 & 0.292 & 0.004 & 0.084 & -0.106 & 0.632 & 0.773 & -0.217 \\
\hline Min & 0.537 & 0.959 & -0.511 & 0.427 & 0.604 & 0.572 & 0.819 & 0.762 & -0.056 & -0.258 & -0.263 & 0.266 \\
\hline Max & 0.393 & 0.246 & -0.036 & 0.449 & 0.504 & 0.756 & 0.622 & 0.387 & -0.387 & -0.335 & -0.351 & -0.023 \\
\hline $\begin{array}{l}\text { Ave. } \\
\text { temp }\end{array}$ & 0.573 & 0.733 & -0.386 & 0.433 & 0.605 & 0.689 & 0.702 & 0.479 & -0.423 & -0.280 & -0.280 & 0.254 \\
\hline
\end{tabular}

Table 3: Correlation coefficients between the climatic variables and malaria prevalence.

For rainfall, there exists positive correlation (ranging between 0.4 between 0.5) in months of March, August, October and November. However, negative correlation $(50 \%)$ was observed in the month of July. The month of February showed very weak positive correlation (0.1) while the months of January, April and September showed very weak negative correlation of 0.1 . There also exists almost no correlation to justify reasonable relationship between malaria and rainfall in the months of May, June and December. Correlations between malaria prevalence and relative humidity in the months of April, May, October and November are strongly positive ranging from 0.6 to 0.8 . There also exists positive correlation $(0.4-0.5)$ in the months of January to February and weak positive correlation (0.1 to 0.3$)$ in the months of June and August. The months of March, September and December have weak negative correlation (0.1-0.2). The correlation coefficient obtained in July is too weak to justify the relationship between malaria prevalence and relative humidity in this study area. For temperatures, demonstrates a good correlation between malaria and the three temperature variables and hence correlation between minimum temperature and malaria was found to be most significant. 


\section{Discussion}

The results obtained in this study shows that the months of March, August, October and November that have relatively strong positive correlation ranging between 0.4 and 0.5 correspond to the period of rainfall onset, little dry season, rainfall cessation and the beginning of dry season respectively. This does not agree with the results obtained by Oluleye and Akinbobola [9], where monthly rainfall had no positive correlation with malaria during wet season but dry season. In this study, monthly amount of rainfall had positive, negative and no correlation with monthly incidences of malaria during rainy seasons. Thus, this confirms that there is an inconsistent relationship between rainfall and malaria incidence in Ibadan. The seemingly inconsistent relationship between rainfall and malaria incidence could result from the saturating effect of rainfall, for an increase in rainfall fails to produce additional malaria cases when aquatic breeding sites are not limiting for mosquitoes [10].

Rainfall onset in March favored breeding of mosquitoes because it was characterized with low amount of rainfall. This finding however corroborates the findings of Ye et al. [11] who found that small amount of rainfall is necessary for transmission to take place. Small amount of rainfall will evaporate and infiltrate quickly over a shorter period and will not cause overflow of water that may flush away mosquito larvae. The ecology of the breeding habitat of mosquitoes is changing and rainfall onset and cessation could affect creation and stability of the breeding habitat. Hydrologic controls on the persistence time of mosquito-breeding sites can be used to regulate mosquito emergence and significantly impact the mosquito development cycle [12]. Further increases in amount of rains in the months after March have negative and no correlation with malaria. The appearance of little dry season in this study area which occurs in august also contributed to mosquitoes reproduction and increased malaria attack because of decreasing rainfall. Although precipitations create mosquitoes' breeding sites [13], malaria was negatively associated with excessive monthly rainfall in Ibadan. Excessive rains may have opposite effect by flushing out small anopheles breeding sites, such as ditches or pools and interrupt the development of mosquito eggs or larvae $[10,14]$. This study however agrees with previous studies. Rain may prove beneficial to mosquito breeding if moderate, but, if excessive it may flush out the mosquito larvae [15].

The negative effect of higher amount of monthly rainfall in this study is well explained with the result obtained in June and July. June, being the first month of rainfall peak showed no significant correlation between malaria and rainfall as July. The month of July that is immediate month after June showed negative correlation. Thus, the effect of higher amount of rainfall in June resulted to decrease in malaria incidence in July. At higher amounts of rainfall, further increases may have little effect on clinical malaria risk, suggesting that a saturation level exists, as reported by Teklehiemanot et al [10]. In this study, beside the effect of the same month's rainfall on malaria transmission, rainfall in the earlier one month also influenced malaria incidence and this result is similar to the study of Gao et al. [16]. This phenomenon could be due to the wet and cooler climatic condition in the month of July which leads to decreasing evaporation or infiltration of water from the surface and therefore caused excess water to flush out breeding larvae. An increase in precipitation does not necessarily produce additional malaria cases when breeding sites are not limited to begin with, and heavy rains and storms can destroy breeding sites, interrupt the development of mosquito eggs and larvae, or flush them out of the pools [4].
In contrast to the effect of higher rainfall amount in June, it is also noted that excessive rains of September (second month of rainfall peak) have no negative effect on malaria incidence in October, a month after. This might be explained by the effect of October's climatic condition which is warmer and dryer than that of September. This enhanced quick evaporation and lowering of water level in the pools to level that could keep water stagnant for breeding mosquitoes. In addition, for rainfall to have a positive effect on malaria incidence, the temperature must be warm enough to support mosquito and parasite development [17]. These findings also similarly confirm the previous report of Danu or et al. [18] that malaria incidence is found to be high at the onset and cessation of the rains but remains generally low during the rainy period.

In this study, positive correlation coefficients indicate the dependence of increased malaria attack on low or moderate rain climatic conditions. The effect of rainfall is not directly related to human infection; but rainfall influences vector population abundance by providing open surface water for breeding. Also, the highest relative humidity of $83-84 \%$ that was experienced in the months of July, August and September was found to subside malaria burden in Ibadan as shown in Table 2 This result supports the findings of Dhiman et al. [19] which observed that, if the average monthly relative humidity is below $55 \%$ and above $80 \%$, the life span of the mosquito gets so shortened that the scope of malaria transmission diminishes. Finally, temperature is a key factor in malaria transmission because it directly affects mosquito development, survival, reproduction, activity, and the extrinsic incubation rate [20-23].

In this study air temperature plays more important role compared to rainfall. It was observed that in spite of high malaria attack in rainy season, the relationship between rainfall and malaria was not as strong as that of temperature and malaria. This is obvious from the high and positive correlation coefficients between mean temperature and malaria in the month of April to August which ranges between 0.4 and 0.7 .

It was observed that as temperature gradually becomes cooler from the months of April to July during rainy season and warmer from the months of December to February during dry season so also the correlation between malaria and temperature becomes stronger

Thus, malaria attack reduces as temperature becomes cooler and increases as temperature becomes warmer. This perhaps suggests that relatively low temperatures are less favorable to malaria transmission in Ibadan. This result also supported Craig et al. [24] which established that temperature affects malaria transmission in various ways, and increase in temperature results in shortened sporogonic period of the Plasmodium parasite within the vector up to about $30^{\circ} \mathrm{C}$. On the other hand, increased temperature is also known to accelerate the development period of the aquatic stages of the vector. Temperature rise is expected to increase transmission and prevalence of malaria by reducing the interval between mosquitoes' blood meals thus decreasing the time to produce new generation, and by shortening incubation period of the parasite in mosquitoes [25].

It was observed that diurnal higher maximum temperature of above $300^{\circ} \mathrm{C}$ have more negative effect on malaria than minimum temperature in warmer months of September to November and less positive effect on malaria in the months of January and February. This shows that exposure to warmer temperatures that exceed the optimum $\left(>300^{\circ} \mathrm{C}\right)$, for at least part of the day, provides something of a negative 
effect, hindering development rate of mosquitoes relative to the cooler mean temperatures in Ibadan.

More so it is obviously seen that average temperature under estimated the effect of minimum temperature on malaria in February, July and August. This indicates that minimum temperature seems to play a more important role in the transmission of the disease than maximum temperature does in Ibadan. This finding further establishes the findings of which concluded that minimum temperatures during the cool months or the previous month have been associated with malaria transmission in China and Burundi respectively.

\section{Malaria hotspots and cold spots in Ibadan central urban area}

The maps depicting presence of statistically significant hotspots and cold spots of malaria over the study period of six years (2010-2015) are shown in Figures 2 and 3. A high and positive Z-score value (in red color) indicates that the clustering is hotspot (surrounded by LGAs with high malaria incidence); whereas a high but negative Z-score value (in blue color) indicates clustering of coldspot (surrounded by other LGAs with low malaria incidence). The higher (or lower) the zscore value, more intense (or less intense) is the cluster of malaria distribution. It can be seen that the intensity of clustering of high values (hot spot) and low value (cold spot) was low and varied throughout the study period, but relatively high in the year 2010, 2011 and 2014.

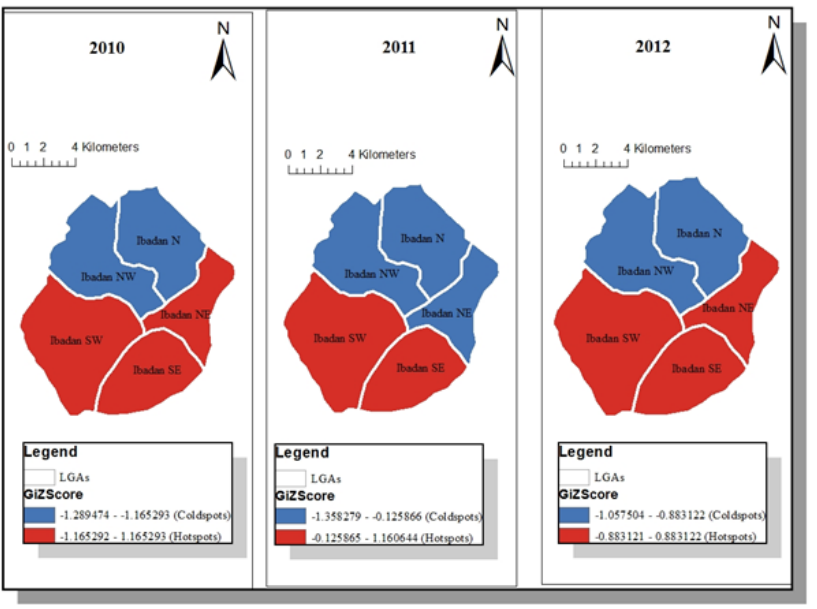

Figure 2: Spatial-temporal hotspots of malaria in Ibadan central urban area (2010-2012).

The statistically significant hotspots of malaria were consistently detected in southern and eastern part of Ibadan central urban area (Ibadan South-West, Ibadan South-East and Ibadan North-East LGAs) and except Ibadan North-East LGA once in 2011. However, Ibadan North and Ibadan North-West LGAs remained malaria cold spot throughout the study period. The delineated stable and consistent areas of malaria hotspots or cold spots may be linked to the uniqueness of geographic features of the area, since the areas are subjected to the same suitable climatic condition for malaria. Most of things relating to malaria is so molded by local conditions that it becomes a thousand epidemiological puzzles [26]. Among the climatic factors impacting on malaria prevalence are rainfall, temperature and relative humidity [24]. However, human ecological and environmental factors like land use
$[27,28]$. And urbanization are Other important aspects for the malaria transmission.

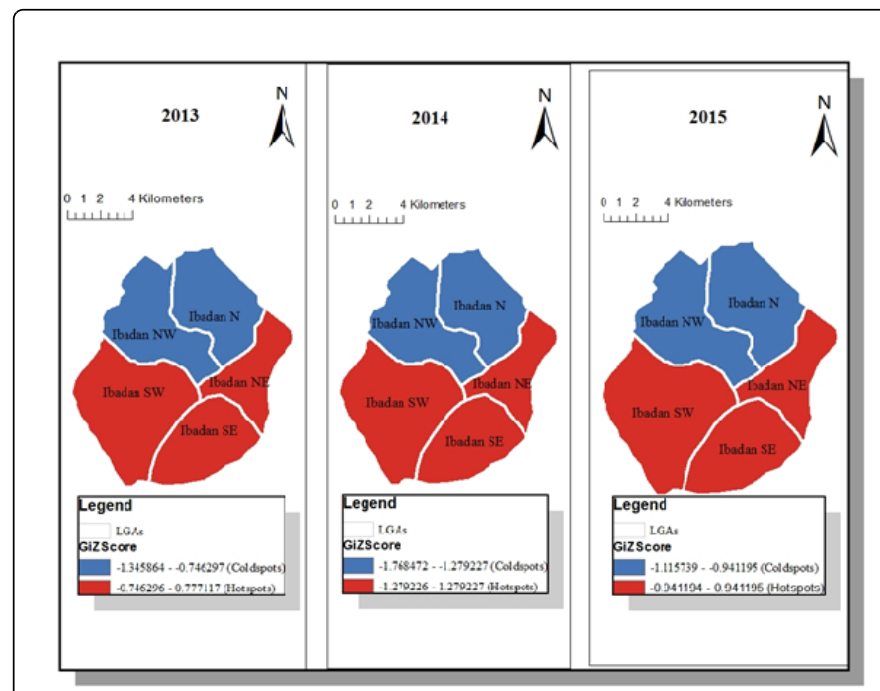

Figure 3: Spatial-temporal hotspots of malaria in Ibadan central urban area (2013-2015).

Moreover, besides climatic factors land use changes may result in malaria hotspots where populations share the same socioeconomic conditions and geographical factors. Land use change can also affect malaria transmission because it modifies the presence or absence of predators, availability of breeding sites, hydrology and topography of an area, vegetation, and, consequently, temperatures Bizimana [29].

\section{Malaria risk level in LGAs}

The malaria risk level in each LGA was observed by overlaying the malaria risk level analysis map and LGAs boundary map. In general, as shown in Figure 2 and Table 4 the whole Ibadan central urban area is dominantly characterized by very high malaria risk zone. All the LGAs were mapped almost fully in very high malaria risk but Ibadan SW, Ibadan SE and Ibadan NE areas of very high risk malaria zone covered more than $96 \%$ of their total areas. This means that Ibadan SW, Ibadan SE and Ibadan NE are in very high risk of malaria incidence and are the most affected LGAs. This seems due to the suitable climatic conditions, topography and proximity to river (Figure 4).

\section{Comparing malaria hotspot and risk maps with LGAs}

The malaria risk map Figure 4 created for the study area corresponded with malaria hotspot maps (Figures 2 and 3). The risk map showed a very high level of malaria tendency in all 5 LGAs but most in Ibadan SW, Ibadan SE and Ibadan NE. According to malaria hotspot map, it can be seen that the LGAs that were affected mostly by malaria are also Ibadan SW, Ibadan SE and Ibadan NE. However, both malaria risk and hotspot maps delineated Ibadan $\mathrm{N}$ and Ibadan $\mathrm{NE}$ as less affected areas. The result of this geographical distribution of malaria across Ibadan central urban area informs malaria control planners, on the most severely affected areas that are mainly located in southern and eastern part, in their decision making. 


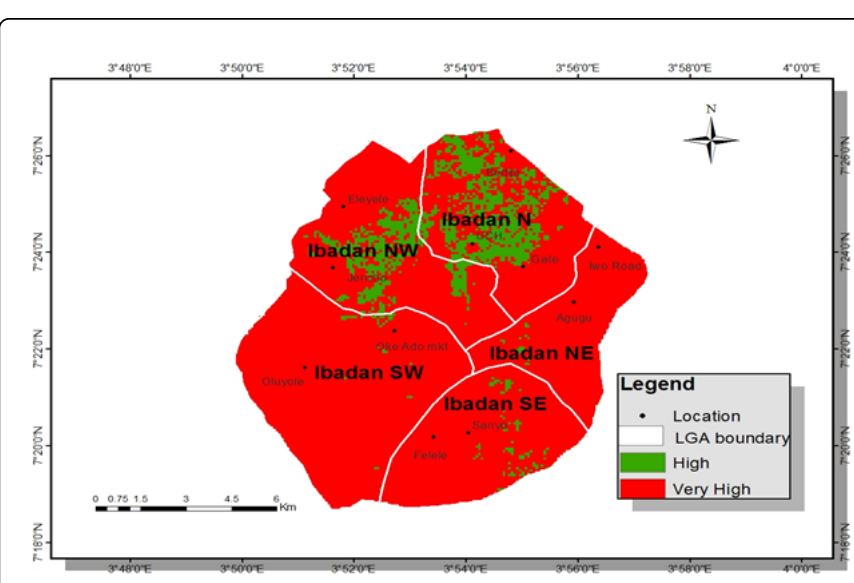

Figure 4: Malaria risk level in LGAs.

\begin{tabular}{|l|l|l|l|}
\hline \multirow{2}{*}{ LGA } & Risk level & Percentage (\%) & Area $\left.\mathbf{( k m}^{2}\right)$ \\
\hline \multirow{3}{*}{ Ibadan N } & High & 6.24 & 8.63 \\
\cline { 2 - 4 } & Very high & 13.14 & 18.17 \\
\hline \multirow{3}{*}{ Ibadan NE } & High & 0.11 & 0.16 \\
\cline { 2 - 4 } & Very high & 12.95 & 17.91 \\
\hline \multirow{3}{*}{ Ibadan NW } & High & 3.8 & 5.25 \\
\hline \multirow{3}{*}{ Ibadan SE } & Very high & 17.12 & 23.68 \\
\hline \multirow{3}{*}{ Ibadan SW } & High & 0.53 & 0.74 \\
\cline { 2 - 4 } & Very high & 16.75 & 23.16 \\
\cline { 2 - 4 } & High & 0.26 & 0.36 \\
\hline
\end{tabular}

Table 4: Malaria risk level in LGAs and their area coverage.

\section{Conclusion}

This study has shown that there is significant relationship between malaria prevalence and climatic variables in the study area. The generated malaria risk map validated the result of Getis-Ord Gi* statistics (hotspot analysis) as they both identified Ibadan SW, Ibadan SE and Ibadan NE LGAs as the areas mostly affected by malaria. This study showed that geospatial technology is very important for analysis of spatial and temporal data and is a vital technique for health sector, particularly to make vector borne diseases prevention and control program effective.

\section{Acknowledgement}

The authors appreciate the Oyo State ministry of health and Nigeria Meteorological agency for the data used. Also, the anonymous reviewers are appreciated

\section{References}

1. Sachs J, Malaney P (2002) The Economic and Social Burden of Malaria. Nature 415: 680-685.
2. World Malaria Report (2009).

3. Hoek WV, Flemming K, Priyanie HA, Devika P, Piyaratne MK, et al. (2003) Towards a risk map of malaria for Sri Lanka: the importance of house location relative to vector breeding sites. International Journal of Epidemiology 32: 280-285.

4. Tian L, Bi Y, Ho SC, Liu W, Liang S, et al. (2008) One-year delayed effect of fog on malaria transmission: a time-series analysis in the rain forest area of Mengla County, south-west China. Malar J 7: 110.

5. Areola O (1994) The spatial growth of Ibadan city and the impact on rural hinterland. (edtn) Ibadan Region. Ibadan: Rex Charles publications: 66-84.

6. Getis A, Ord JK (1995) Local spatial autocorrelation statistics: distributional issues and an application. Geographical Analysis 27: 286-306.

7. Getis A, Ord JK (1996) Local spatial statistics, Spatial Analysis: Modelling in GIS Environment New York John Wiley \& Sons Inc: 261-277

8. Getis A, Ord J (1992) The analysis of spatial association by use of distance statistics. Geographical Analysis 24: 189- 206.

9. Oluleye A, Akinbobola A (2010) Malaria and pneumonia occurrence in Lagos, Nigeria: role of temperature and rainfall. Afr J Environ SciTechnol 4: 506-516.

10. Teklehaimanot HD, Lipsitch M, Teklehaimanot A, Schwartz J (2004) Weather-based prediction of Plasmodium falciparum malaria in epidemic-prone regions of Ethiopia I. Patterns of lagged weather effects reflect biological mechanisms. Malar J 3: 41.

11. Yé Y, Louis V, Simoboro S, Sauerborn R (2007) Effect of meteorological factors on clinical malaria risk among children, using village-based meteorological stations and community-based parasitological survey. BMC Pub Health 7: 101.

12. Gianotti R, Bomblies A, Eltahir E (2009) Hydrologic modeling to screen potential environmental management methods for malaria vector control in Niger. American Geophysical Union.

13. McMichael AJ, Martens WJM (1995) The health impact of global climate change grappling with scenarios, predictive models and multiple uncertainties. Ecosyst Health 1: 15-25.

14. JA Patz, AK Githeko, JP McCarty, S Hussain, Confalonieri U, de N (2003) Wet Climate change and infectious diseases. Word Health Orgnization.

15. Paaijmans KP, Wandago MO, Githeko AK, Takken W (2007) Unexpected High Losses of Anopheles gambiae Larvae Due to Rainfall. PLoS ONE 2: e1146.

16. Gao HW, Wang LP, Liang S, Liu YX, Tong SL, et al. (2012) Change in Rainfall Drives Malaria Re-Emergence in Anhui Province, China. PLoS ONE7: e43686.

17. Bodker R, Akida J, Shayo D, Kisinza W, Msangeni HA, et al. (2003) Relationship between altitude and intensity of malaria transmission in the Usambara Mountains, Tanzania. J Med Entomol 40: 706-717.

18. Danuor SK, Tay SCK, Annor T, Forkuo EK, Bosompem KM, et al. (2010) The impact of climate variability on malaria incidence and prevalence in the forest zone of Ghana - A case study at two hospitals located within the Kumasi Metropolitan area of the Ashanti Region of Ghana; 2nd International Conference: Climate, Sustainability and Development in Semi-arid Regions, Fortaleza - Ceará, Brazil.

19. Dhiman S, Gopalakrishnan R, Goswami D, Baruah I, Singh L (2010) Malaria epidemiology along Indo-Bangladesh border in Tripura state, India. South East Asian J Trop Med Pub Hlth 41: 1279-1289.

20. Zhou G (2004) Association between climate variability and malaria epidemics in the East African highlands. Proc Natl Acad Sci U S A 101: 2375-2380.

21. Bi P, Tong SL, Donald K, Parton KA, Ni JF (2003) Climatic variables and transmission of malaria: A 12-year data analysis in Shuchen County, China. Public Health Rep 118: 65-71.

22. Zhou GF, Minakawa N, Githeko AK, Yan GY (2005) Climate variability and malaria epidemics in the highlands of East Africa. Trends Parasitol $21: 54-56$. 
Citation: Akinbobola A, Ikiroma IA (2018) Determining Malaria Hotspot Using Climatic Variables and Geospatial Technique in Central Urban Area of Ibadan, Southwest, Nigeria. J Climatol Weather Forecasting 6: 225. doi:10.4172/2332-2594.1000225

Page 7 of 7

23. Pascual M, Ahumada JA, Chaves LF, Rodo X, Bouma M (2006) Malaria resurgence in the East African highlands: temperature trends revisited. Proc Natl Acad Sci USA 103: 5829-5834.

24. Craig MH, RW Snow, DLe Sueur (1999) A climate based distribution model of malaria transmission in Sub Saharan Africa Parasitol Today 15: $105 Đ 111$.

25. Nkurunziza H, Gebhardt A, Pilz J (2010) Bayesian modelling of the effect of climate on malaria in Burundi: Malaria Journal 9: 114.

26. Ceccato P, Ghebremeskel T, Jaiteh M (2007) Malaria stratification, climate and epidemic early warning in Eritrea. The American Journal of Tropical Medicine and Hygiene 77: 61-68.
27. Munga S, Minakawa N, Zhou G, Mushinzimana E, Barrack OO, et al. (2006) Association between land cover and habitat productivity of malaria vectors in western Kenyan highlands. Am J Trop Med Hyg 74: 69-75.

28. Hay SI, Cox J, Rogers DJ, Randolph SE, Stern DI, et al. (2002) Climate change and the resurgence of malaria in the East African highlands. Nature 415: 905-909.

29. Bizimana JP, Twarabamenye E, Kienberger S (2015) Assessing the social vulnerability to malaria in Rwanda: Malaria Journal 14: 2. 